\title{
Trabalhar sobre a memória
}

\author{
Maria Helena Serôdio
}

\author{
Fazemos isto para trabalhar, para criticar a memória da humanidade. \\ É este o nosso ofício, trabalhar sobre esta memória. \\ Antoine Vitez
}

São de Antoine Vitez as frases em epígrafe e são citadas por Alexandra Moreira da Silva na declaração com que justifica o Prémio da Crítica entregue - no passado mês de Março, no belo Salão de Inverno do São Luiz Teatro Municipal - às Comédias do Minho, na pessoa do seu actual Director Artístico, João Pedro Vaz.

Julgo que, em grande medida, é por essa vontade de preservar e, ao mesmo tempo, reformular a memória, que o teatro, a escrita para teatro e a escrita sobre teatro se vão cumprindo. Disso mesmo nos fala também Marvin Carlson no seu precioso livro sobre a assombração que marca todos os componentes do teatro: o palco, o texto, o corpo, a produção e a casa-teatro (Carlson 2003). É, de facto, sua convicção que o teatro é a "estrutura cultural em que mais pesa a assombração [...], o verdadeiro repositório da memória cultural" (Ibidem: 2). Cita, de resto, muitos outros teóricos e criadores de teatro que com ele convergem neste mesmo entendimento, como Richard Schechner, Herbert Blau, ou Elin Diamond, entre muitos outros.

Não se trata, porém, de uma opção passadista, da anulação do presente, da recusa do novo. É apenas a consciencialização de que o humano e - por isso também - a arte necessariamente integram essa outra dimensão. E dessa dupla vertente falou ainda Antoine Vitez, negando justamente que a arte possa preservar sem alterar, ou alterar sem preservar:

A tradição conserva, sim, mas pela mudança, e essa obrigação é-nos imposta por um Mandamento secreto, obscuro, uma espécie de danação ou condenação para que se não perca a memória. (Vitez 1989:5)

Ao longo do percurso que fomos cumprindo desde que esta revista foi criada - em 2004 - foram já muitos os nomes de artistas, críticos, historiadores, autores, companhias, espectáculos, livros, salas de teatro, que estudámos, criticámos e avaliámos. Fizemo-lo ombro a ombro com muitos outros que, de modo pontual ou continuado, nos vêm acompanhando. Alguns dos mais queridos, dos mais entusiastas, dos mais sabedores deixaram-nos para sempre e, com a sua ausência, instalouse uma imensa nostalgia, um continuado sentimento de perda. Mas também esse tal "Mandamento secreto" para que se não perca a memória.

É por eles também - e com o legado que nos deixaram e que habita já esta revista - que prosseguimos neste nosso trabalho de memória. Carlos Porto, Paulo Eduardo Carvalho, agora Luiz Francisco Rebello integram a nossa memória e residem em permanência nas páginas desta revista. É também por eles e para eles que continuamos a escrever!

Também desde o $1 .^{\circ}$ número que fomos lembrando alguns dos artistas que nos deixaram, e já foram tantos... Fiama Hasse Pais Brandão, Raul Solnado, António Feio, João Paulo Seara Cardoso, Mário Alberto, Mário Barradas, Isabel Alves Costa entre vários outros.

Cabe neste número um texto de Christine Zurbach que avalia justamente um espectáculo de memória que o CENDREV criou para recordar Mário Barradas - Café Mário -, lembrando o trabalho notável do actor e encenador que ele foi e a quem se deve um extraordinário dinamismo na criação daquela casa e escola de teatro (antes de ser CENDREV foi CCE - Centro Cultural de Évora) o que, de algum modo, lançou o movimento da descentralização depois de Abril de 1974 e que tão grande impacto teve na vida teatral entre nós.

Em duas outras secções evocamos o inexcedivel trabalho de Luiz Francisco Rebello que em Dezembro de 2011 nos deixou. Recordamo-lo como exímio historiador e ensaista do teatro português (nos "Estudos aplicados") e como dramaturgo de grande competência artística, que soube corajosamente abordar temáticas fracturantes nas suas inspiradas dramaturgias, como bem assinala Sebastiana Fadda na abertura do "Portefólio" que todos Ihe dedicamos.

Outras memórias ocupam mais páginas deste nosso número. Na secção "Leituras", Isabel Pinto recorda a homenagem a Stephen Reckert em livro, Ana Isabel Vasconcelos recenseia o volume que Eugénia Vasques publicou sobre o Conservatório, e Miguel Honrado apresenta o belo livro, este também memorialístico, que Jorge Salavisa recentemente lançou pela editora D. Quixote. Nos "Estudos aplicados" Daniel Rosa traz-nos notícia sobre a revelação do teatro japonês em Portugal, no início do séc. XX, com a presença de Saddayakko (ou Sada Yacco) e Otojiro Kawakami.

A condição de críticos - sobre que assenta em grande medida esta revista que é, de resto, propriedade da Associação Portuguesa de Críticos de Teatro - abre ainda neste número para dois textos que ponderam a reflexão a que obriga essa prática. Um deles decorre de uma aturada investigação que conduziu a uma excepcional tese de 
Mestrado (apresentada à Faculdade de Letras da Universidade de Lisboa) e que a autora - Elisabeth Costa - retoma em incursão breve para o "Arquivo solto", recordando o brilhante e belicoso Joaquim Madureira, que assinava as suas criticas de teatro como Braz Burity. 0 outro texto, de Rui Pina Coelho para as "Notícias de fora", decorre do congresso da Associação Internacional de Críticos de Teatro (AICT-IATC), que se reuniu em Varsóvia no passado mês de Março, e no âmbito do qual foi possivel assistir a importantes criações teatrais que ele aqui recorda com um extraordinário sentido analítico.

Sobre criações contemporâneas, que por aqui se apresentaram ou que radicam em valores artísticos muito nossos, podemos ler observações interessantes tanto no "Dossiê temático" como nas secções "Passos em volta", "Estudos aplicados" e "Na primeira pessoa". Neste último caso, Bruno Bravo fala - a Emilia Costa e Ana Bigotte Vieira - sobre o seu trabalho como actor e encenador nos Primeiros Sintomas, articulando o que é a sua prática artística na relação privilegiada com o dramaturgo Migue Castro Caldas. No caso do "Dossiê temático", que inclui as declarações do júri sobre o Prémio da Crítica relativo a 2011, lemos declarações judicativas sobre o trabalho de Mónica Calle na Casa Conveniente (por Rui Monteiro), o de Joana Craveiro e o Teatro do Vestido (por João Carneiro) o de Gonçalo Amorim (por Maria Helena Serôdio)e a reflexão crítica de maior fôlego de Alexandra Moreira da Silva sobre as Comédias do Minho. Constança Carvalho Homem, que presidiu à sessão da atribuição do Prémio, sinaliza, na abertura desta secção, a convergência dos premiados numa "geografia improvável" que habitam e a que preside uma declarada "resiliência".

Nos "Estudos aplicados", ainda, Gustavo Vicente fala das novas dramaturgias de palco em "Geração sem fronteiras" e, nos "Passos em volta", outros criadores são evocados: As Boas Raparigas (pela reflexão de Constança Carvalho Homem), o Teatro Experimental do Porto em coprodução com os Primeiros Sintomas (na análise de Emilia Costa), o Teatro dos Aloés (na crítica de Rui Pina Coelho), o Teatro Experimental do Porto (sobre peça de Rui Pina Coelho, por Maria Helena Serôdio), e a co-produção de Ao Cabo Teatro, Guimarães 2012 - Capital Europeia da Cultura, São Luiz Teatro Municipal, Teatro Nacional S. João para a recriação de Medida por medida, que Francesca Rayner avalia criticamente. Nesta secção incluímos ainda um conjunto de apontamentos críticos subscritos por jovens críticos sobre o festival Odisseia, que decorreu no Porto em 2011, e que resultaram de um "Seminário para novos críticos", da Associação Portuguesa de Críticos de
Teatro, coordenado por Alexandra Moreira da Silva e Constança Carvalho Homem. Foi por lapso que este texto não saiu no número anterior desta nossa revista, pelo que pedimos desculpa aos autores e a quem pacientemente coordenou estes trabalhos.

Ainda em discurso crítico surge a evocação analítica de realidades teatrais e criativas de outras paragens:

Susana Chicó fala do festival Forest Fringe que nos visitou na Culturgest (em "Passos em volta"), Ana Bigotte Vieira recorda um espectáculo de Meg Stuart (em "Notícias de fora"), e Daniele Avila Small relata a nova aventura da crítica brasileira em publicação electrónica Questão de critica (na secção "Em rede"). Uma mais elaborada reflexão teórica é aqui trazida (na secção "Estudos aplicados") por Anabela Mendes que abre campo a uma questionação sobre "os parâmetros cognitivos aplicados a públicos de teatro e outras artes", deste modo enunciando metódica e exemplarmente os passos necessários para uma Sociologia das Artes do Espectáculo.

Se os conteúdos aqui referidos garantem um valor inquestionável a este número da Sinais de cena, é importante sublinhar que ele é permitido pela enorme dedicação de quem os escreve, mas também de quem generosamente apoia de muitas outras formas: esclarecendo dúvidas, disponibilizando fotografias, apoiando em tantos outros gestos de compreensão e companheirismo. Em termos institucionais, o nosso agradecimento vai para o Centro de Estudos de Teatro da Faculdade de Letras da Universidade de Lisboa (apoiante ousado e pródigo desde o seu primeiro número) e para o Museu Nacional do Teatro (na amável cedência de fotografias e dilucidação de dúvidas).

Uma gratidão especial é devida ao Instituto Camões - que começou a disponibilizar a nossa revista, os seus primeiros nove números em pdf, no seu sítio electrónico - e às três instituições que generosamente aceitaram incluir aqui publicidade às suas actividades: o Teatro Nacional D. Maria II, o Teatro Nacional S. João e a Sociedade Portuguesa de Autores.

Sem estes apoios este número não teria existido!

\section{Referências bibliográficas}

CARLSON, Marvin (2003), The Haunted Stage: The Theatre as Memory Machine. Ann Arbor, The University of Michigan Press. VITEZ, Antoine (1989), "Antoine Vitez à Chaillot ", L'art du théâtre, Arles, Actes Sud, n. ${ }^{\circ}$ 10, Hiver-Printemps. 